\title{
Microbial Community Dynamics
} During the Non-filamentous Fungi Growth-Based Fermentation Process of Miang, a Traditional Fermented Tea of North Thailand and Their Product Characterizations

\begin{abstract}
Kridsada Unban ${ }^{1}$, Nuttapong Khatthongngam ${ }^{1}$, Thanawat Pattananandecha ${ }^{2}$, Chalermpong Saenjum ${ }^{2}$, Kalidas Shetty ${ }^{3}$ and Chartchai Khanongnuch ${ }^{1,4 *}$
\end{abstract}

OPEN ACCESS

Edited by:

Analia Graciela Abraham National University of La Plata,

Argentina

Reviewed by:

Jyoti Prakash Tamang,

Sikkim University, India

Ruben F. Gonzalez-Laredo,

Durango Institute of Technology,

Mexico

${ }^{*}$ Correspondence:

Chartchai Khanongnuch chartchai.k@cmu.ac.th;

ck_biot@yahoo.com

Specialty section: This article was submitted to

Food Microbiology,

a section of the journa

Frontiers in Microbiology

Received: 02 March 2020 Accepted: 10 June 2020

Published: 14 July 2020

Citation:

Unban K, Khatthongngam $N$, Pattananandecha T, Saenjum C, Shetty K and Khanongnuch C (2020)

Microbial Community Dynamics

During the Non-filamentous Fungi Growth-Based Fermentation Process of Miang, a Traditional Fermented Tea of North Thailand and Their Product

Characterizations.

Front. Microbiol. 11:1515. doi: 10.3389/fmicb.2020.01515
'Division of Biotechnology, School of Agro-Industry, Faculty of Agro-Industry, Chiang Mai University, Chiang Mai, Thailand, ${ }^{2}$ Department of Pharmaceutical Sciences, Faculty of Pharmacy, Chiang Mai University, Chiang Mai, Thailand, ${ }^{3}$ Global Institute of Food Security and International Agriculture (GIFSIA), Department of Plant Sciences, North Dakota State University, Fargo, ND, United States, ${ }^{4}$ Research Center for Multidisciplinary Approaches to Miang, Chiang Mai University, Chiang Mai, Thailand

Miang, a traditional fermented tea leaf (Camellia sinensis var. assamica) consumed in northern Thailand, was simulated in laboratory conditions using non-filamentous fungi process (NFP) and microbial community was periodically investigated for over 6 months of fermentation by both culture-dependent and -independent techniques. The viable cell numbers of lactic acid bacteria $(\angle A B)$, yeast, and Bacillus enumerated by the culture-dependent technique markedly surged over 3 days of initial fermentation and then smoothly declined by the end of fermentation. $L A B$ were found as the main microbial population throughout the fermentation period followed by yeast and Bacillus. High-throughput sequencing of microbial community during fermentation revealed that Firmicutes (86.9-96.0\%) and Proteobacteria (4.0-12.4\%) were the dominant bacterial phyla, whereas Ascomycota was found to be the main fungal phylum with an abundance of over $99 \%$ in the fungal community. The dominant bacterial family was Lactobacillaceae (39.7-79.5\%) followed by Acetobacteraceae, Enterobacteriaceae, Bacillaceae, Aeromonadaceae, Staphylococcaceae, Moraxellaceae, Clostridiaceae, Exiguobacteraceae, Streptococcaceae, and Halomonadaceae. Meanwhile, the main fungal family was incertae sedis Saccharomycetales (75.6-90.5\%) followed by Pichiaceae, Pleosporaceae, Botryosphaeriaceae, Davidiellaceae, Mycosphaerellaceae, and Saccharomycodaceae. In addition, Lactobacillus (29.2-77.2\%) and Acetobacter (3.8-22.8\%), and the unicellular fungi, Candida (72.5-89.0\%) and Pichia (8.1-14.9\%), were the predominant genera during the fermentation process. The profiles of physical and chemical properties such as Miang texture, $\mathrm{pH}$, organic acids, polysaccharidedegrading enzyme activities, and bioactive compounds have rationally indicated the microbial fermentation involvement. $\beta$-Mannanase and pectinase were assumed to be 
the key microbial enzymes involved in the Miang fermentation process. Total tannin and total polyphenol contents were relatively proportional to the antioxidant activity. Lactic acid and butyric acid reached maximum of 50.9 and $48.9 \mathrm{mg} / \mathrm{g}$ dry weight (dw) at 9 and 63 days of fermentation, respectively. This study provided essential information for deeper understanding of the Miang fermentation process based on the chemical and biological changes during production.

Keywords: fermented tea, Miang, microbial community, antioxidants, fermentation

\section{INTRODUCTION}

Miang is a traditionally consumed after-meal chewed food product from fermented Assam tea leaves (Camellia sinensis var. assamica) produced by naturally occurring bacteria and fungi, and has been used for hundreds of years in the northern part of Thailand. Traditional Miang is prepared by fermentation of steamed tea leaves in a container such as a bamboo basket without adding other nutritional substances for several days or up to a year (Khanongnuch et al., 2017). Miang fermentation processes can be categorized into two processes: filamentous fungi growth-based process (FFP) and non-filamentous fungi growth-based process (NFP) (Khanongnuch et al., 2017). The FFP type is processed by two main steps, where a bunch of steamed tea leaves in succession allows the growth of filamentous fungi under aerobic conditions for 5-10 days and then followed by the anaerobic fermentation at an ambient temperature for 35 days. Differing from the FFP process, the NFP type does not require the growth of initial filamentous fungi, where the steamed tea leaves are directly fermented under anaerobic conditions and kept at ambient temperature for 1-4 weeks to 3-12 months. Recently, nutritional biotransformation in both types of Miang was evaluated, and it was found that the quality of Miang is affected by the microflora involved, the quality of tea leaves, and the fermentation process, which are different depending on the production area (Unban et al., 2019). During the fermentation process, the nutritional components of steamed tea leaves such as proteins, carbohydrates, and lipids are utilized by various microorganisms derived from the surrounding environment through an enzyme-linked catalytic biotransformation process for producing the various metabolites such as organic acids, amino acids, and health-relevant bioactive metabolites. Through biotransformation of macronutrients in Miang, some additional beneficial bioactive compounds such as phenolic metabolites are expected, which have health-relevant benefits beyond basic nutrition as is well-known in green tea and tea-related products that include catechins and derivatives, gallic acids, and tannins (Kawakami et al., 1987; Huang et al., 2016; Zhu et al., 2020). Various kinds of microorganisms participate in Miang fermentation and produce unique flavors, odor, and tastes. It has been reported that L. plantarum is the dominant species in Miang and plays important roles during fermentation (Okada et al., 1986). Many studies have reported that lactic acid bacteria (LAB), including Lactobacillus pentosus, Lactobacillus vaccinostercus, Enterococcus casseliflavus, Enterococcus camelliae, Lactobacillus thailandensis, Lactobacillus camelliae, and Pediococcus siamensis, are involved in Miang fermentation (Sukontasing et al., 2007; Tanasupawat et al., 2007). Moreover, yeast analysis in Miang sample collected from 28 sampling sites including eight provinces in upper northern Thailand reported that Candida ethanolica is the dominant species (Kanpiengjai et al., 2016). Recently, the significant presence of endospore forming bacteria were detected from 40 Miang samples with the average number ranging from 40 to $45 \%$ of total bacterial counts in Miang samples (Unban et al., 2019). However, these studies were based on culture-dependent methods and were limited to identifying the microorganisms, which grow on specific nutrient media. This approach of using only the culturable microorganisms may not reflect the true microbial composition of Miang.

Recent advances in high-throughput sequencing technology by using Illumina HiSeq platform are changing the way to investigate the microbial communities where a large number of sequences can be analyzed at comparatively low cost, increasing the depth of sequencing for understanding the dynamics of microbial community (Loman et al., 2012). It has already been successfully used to elucidate the complex microbial community in fermented vegetable food, traditional fermented soybean food, and fermented tea leaves in Myanmar (Liang et al., 2018; Bo et al., 2020; Tan et al., 2020). This high-throughput sequencing technology was applied for the first time to investigate the dynamic changes in the bacterial and fungal communities in Miang fermentation. Therefore, in the current study, the bacterial and fungal community dynamics and changes in healthrelevant bioactive compounds in Miang fermentation by the non-filamentous fungi-based process were carried out using $16 \mathrm{~S}$ rRNA gene sequencing and ITS region sequencing using Illumina HiSeq platform to investigate relationships between bioactive compound and composition of the Miang microbial community during fermentation.

\section{MATERIALS AND METHODS}

\section{Miang Preparation and Sampling}

The NFP Miang samples were prepared at a local Miang producing plant (Papae district, Chiang Mai, Thailand) following the traditional method as described previously (Khanongnuch et al., 2017). Briefly, fresh young Assam tea leaves (C. sinensis var. assamica) were steamed for $3 \mathrm{~h}$. Immediately after steaming, the leaves were spread on a bamboo tray and allowed to cool for $3 \mathrm{~h}$ in an open space. The 100-g portions of steamed leaves were wrapped with $70 \%(\mathrm{v} / \mathrm{v})$ ethanol surface-sterilized banana 
leaves and were tightly packed in polyethylene plastic bags (polyethylene bags, $17.7 \times 25.4 \mathrm{~cm}$ ) and then all samples were promptly transported in an ice box to laboratory. Miang samples were incubated in a dark chamber to allow natural fermentation at ambient temperature $\left(28 \pm 2^{\circ} \mathrm{C}\right)$ for 180 days. Periodically over the fermentation period, Miang samples were collected every 3 days for a month and a week for 180 days. Samples were kept at $-20^{\circ} \mathrm{C}$ for testing in triplicate at each time point.

\section{Enumeration of Microorganism by Culture-Dependent Methods}

Total numbers of viable bacterial and yeast cells in Miang samples were enumerated as described previously (Unban et al., 2019). Briefly, $50 \mathrm{~g}$ of Miang sample was mixed with $200 \mathrm{ml}$ of sterile $0.85 \%(\mathrm{w} / \mathrm{v})$ sodium chloride solution and homogenized by a Masticator homogenizer (IUL Instruments, Barcelona, Spain) for $10 \mathrm{~min}$. The diluted samples from $10^{-2}$ to $10^{-8}$ were spread on nutrient agar (NA); deMan, Rogosa, and Sharpe (MRS) agar supplemented with $0.015 \%(\mathrm{w} / \mathrm{v})$ bromocresol purple; and Sabouraud dextrose agar (SDA) supplemented with $100 \mathrm{mg} / \mathrm{l}$ chloramphenicol for enumeration of total viable bacteria, LAB, and yeast, respectively. The remaining diluted samples were incubated in a water bath at $80^{\circ} \mathrm{C}$ for $12 \mathrm{~min}$, and then the proper diluted solutions were spread on NA for counting of endospore-forming bacteria presumptively assumed to be Bacillus sp. (Santana et al., 2008). The agar plates were incubated at $30^{\circ} \mathrm{C}$ for 3 days and the microbial numbers were calculated as colony-forming units (CFU) per gram of sample.

\section{Extraction of Genomic DNA}

Five portions of each Miang sample were randomly collected from different parts of the whole sample and $1 \mathrm{~g}$ of each portion was extracted for total genomic DNA using DNeasy Power Soil Kit (Qiagen, Valencia, CA, United States), following the instruction of the manufacturer. DNA quality and quantity were assessed by ratios of 260/280 $\mathrm{nm}$ and 260/230 $\mathrm{nm}$. Genomic DNA was stored at $-20^{\circ} \mathrm{C}$ until further processing. A combination of five total genomic DNA extracts from Miang sample $(100 \mu \mathrm{l}$ each) was pooled in one 1.5-ml tube, mixed well, and used as final genomic DNA template for PCR amplification of both bacterial 16S rRNA and fungal ITS rRNA genes.

\section{Amplicon Sequencing of 16S rRNA Gene}

The V3-V4 region of bacterial 16S rRNA gene was amplified using the primers $341-\mathrm{F}$ ( $5^{\prime}$-CCT AYG GGR BGC ASC AG-3') and 806-R ( $5^{\prime}$-GGA CTA CNN GGG TAT CTA AT-3') with a specific barcode at the $5^{\prime}$ end. The PCR reactions were carried out with Phusion ${ }^{\circledR}$ High-Fidelity PCR Master Mix (New England Biolabs, Beverly, MA, United States). Thermal cycling conditions used were as follows: $5 \mathrm{~min}$ initial denaturation at $95^{\circ} \mathrm{C} ; 25$ cycles of denaturation at $95^{\circ} \mathrm{C}(30 \mathrm{~s})$; annealing at $56^{\circ} \mathrm{C}(30 \mathrm{~s})$, elongation at $72^{\circ} \mathrm{C}(40 \mathrm{~s})$; and final extension at $72^{\circ} \mathrm{C}$ for 10 min. The PCR products were separated by $2 \%(\mathrm{w} / \mathrm{v})$ agarose gel electrophoresis. All PCR products were mixed and purified with the Qiagen Gel Extraction Kit (Qiagen, Germany). The sequenced libraries of bacterial $16 \mathrm{~S}$ rRNA genes were generated for high-throughput sequencing using TruSeq ${ }^{\circledR}$ DNA PCR-Free Sample Preparation Kit (Illumina, San Diego, CA, United States) following the manufacturer's recommendations and index codes were added. The library quality was assessed on the Qubit@ 2.0 Fluorometer (Invitrogen, Thermo Scientific, CA, United States) and Agilent Bioanalyzer 2100 system (Agilent Technologies, Palo Alto, CA, United States). Then, the library was sequenced on an Illumina HiSeq2500 platform (Illumina, San Diego, CA, United States) by Novogene Bioinformatics Technology Co., Ltd. (Beijing, China).

\section{Amplicon Sequencing of ITS Region}

The ITS rRNA gene of fungi was amplified with the forward primer ITS3 (5'-GCA TCG ATG AAG AAC GCA GC-3') and the reverse primer ITS4 (5'-TCC TCC GCT TAT TGA TAT GC$\left.3^{\prime}\right)$ with a specific barcode at the $5^{\prime}$ end. The PCR reactions were carried out with Phusion High-Fidelity PCR Master Mix (New England Biolabs, Beverly, MA, United States). Thermal cycling conditions used were as follows: $5 \mathrm{~min}$ initial denaturation at $95^{\circ} \mathrm{C}$; 25 cycles of denaturation at $95^{\circ} \mathrm{C}(30 \mathrm{~s})$; annealing at $56^{\circ} \mathrm{C}$ (30 s), elongation at $72^{\circ} \mathrm{C}(40 \mathrm{~s})$; and final extension at $72^{\circ} \mathrm{C}$ for $10 \mathrm{~min}$. The PCR products were separated by $2 \%$ agarose gel electrophoresis. All PCR products were mixed and purified with the Qiagen Gel Extraction Kit (Qiagen, Germany). The sequenced libraries of fungal ITS rRNA genes were generated for high-throughput sequencing using TruSeq DNA PCR-Free Sample Preparation Kit (Illumina, San Diego, CA, United States) following the manufacturer's recommendations, and index codes were added. The library quality was assessed on the Qubit@ 2.0 Fluorometer (Invitrogen, Thermo Scientific, CA, United States) and Agilent Bioanalyzer 2100 system (Agilent Technologies, Palo Alto, CA, United States). Then, the library was sequenced on an Illumina HiSeq2500 platform (Illumina, San Diego, CA, United States) by Novogene Bioinformatics Technology Co., Ltd. (Beijing, China).

\section{Bioinformatics}

The raw sequencing reads obtained from Illumina platform were then merged using FLASH software (FLASH v1.2.7) (Magoč and Salzberg, 2011) and filtered with the QIIME software (Version 1.7) (Caporaso et al., 2010). After quality control, all quality filtered sequencing reads were clustered into operational taxonomic units (OTUs) with a threshold of 97\% sequence similarity by utilizing UPARSE software (Version 7.0) (Edgar, 2013). Species classification of the processed bacterial OTU was performed using the Greengenes Database based on Ribosomal Database Project (RDP) classifier 2.2 algorithm (Desantis et al., 2006). The Unite Database was used on BLAST algorithm for fungal representative sequence, which was calculated by QIIME software (Kõljalg et al., 2013). The OTUs abundance information was normalized by utilizing a standard sequence number corresponding to the sample with the least sequences.

\section{Statistical Analysis}

The alpha diversity indices, including Shannon-Weaver index (Shannon and Weaver, 1963), Cho1 index (Chao, 1987), and Good's coverage values, were calculated by QIIME (Version 
1.7) ${ }^{1}$ and displayed with $\mathrm{R}$ software (Version 2.15.3). Principal component analysis (PCA) based on the relative abundance of microbiota during the fermentation of Miang was performed using the FactoMineR package and ggplot2 package in $\mathrm{R}$ software (Version 2.15.3).

\section{pH and Total Acid}

The $\mathrm{pH}$ of Miang samples was measured using a $\mathrm{pH}$ meter (OHAUS starter 2100 pH meter, Pine Brook, NJ, United States), and the total acid was determined by titration method as described by the Association of Official Analytical Chemists (AOAC, 2012). Briefly, $10 \mathrm{~g}$ of sample was suspended in $100 \mathrm{ml}$ of sterile distilled water and homogenized for $10 \mathrm{~min}$ with a Masticator homogenizer (IUL Instruments, Barcelona, Spain) and then the supernatant was separated by centrifugation at $10,000 \times g$ at $4^{\circ} \mathrm{C}$ for $10 \mathrm{~min}$. The supernatant was used for $\mathrm{pH}$ measurement and total acid determination by the $\mathrm{NaOH}$ titration method.

\section{Organic Acid and Catechins Analysis}

Eight major organic acids, including glucuronic acid, tartaric acid, lactic acid, acetic acid, citric acid, succinic acid, gallic acid, and butyric acid, in the Miang sample were determined using the method of Han et al. (2019) with slight modifications. Briefly, the analysis was conducted using an Agilent 1200 reversed-phase HPLC coupled with a UV detector equipped with Luna Omega Polar C18 UHPLC column $(150 \mathrm{~mm} \times 3.0 \mathrm{~mm}, 1.6-\mu \mathrm{m}$ particle diameters, Phenomenex). The column was operated using $20 \mathrm{mM}$ $\mathrm{KH}_{2} \mathrm{PO}_{4}$ as a mobile phase with a flow rate of $0.6 \mathrm{ml} / \mathrm{min}$. The UV detection wavelength was set at 210 and $254 \mathrm{~nm}$ and the barbituric acid was used as the internal standard. All samples were analyzed in triplicate. The contents of extracted catechins and related compounds from Miang samples were analyzed by a reversed-phase HPLC using Agilent 1200 equipped with the Symmetry Shield RP18 column $(4.6 \mathrm{~mm} \times 250 \mathrm{~mm}, 5-\mu \mathrm{m}$ particle diameters, Water Co., Ltd.). The column was operated at a flow rate of $1.0 \mathrm{ml} / \mathrm{min}$ using $10 \%$ acetonitrile in $0.1 \%$ acetic acid and $\mathrm{H}_{2} \mathrm{O}$ as mobile phase. The peaks were detected using a UV detector at 210 and $270 \mathrm{~nm}$. All samples were measured in triplicate.

\section{Texture and Color Analysis}

Texture profile analysis of the Miang sample was performed in terms of hardness using TA-XTplus Texture Analyser (Stable Micro Systems, Surrey, United Kingdom) in TPA mode. Quantitative evaluation of Miang surface color was measured by a portable tristimulus colorimeter (Minolta Chroma Meter CR-300, Osaka, Japan), and the result was presented by the $\mathrm{L}^{*} \mathrm{a}^{*} \mathrm{~b}^{*}$ color coordinate system $\left(\mathrm{L}^{*}=\right.$ lightness, $\mathrm{a}^{*}=$ redness, and $\mathrm{b}^{*}=$ yellowness). Five spots were randomly selected for color measurement on individual samples and presented as the average value.

\footnotetext{
${ }^{1}$ http://qiime.org/tutorials/tutorial.html
}

\section{Determination of Polysaccharide-Degrading Enzymes}

The polysaccharide-degrading enzyme activities (i.e., $\beta$-mannanase, cellulase, xylanase, amylase and pectinase) in Miang samples were investigated. $\beta$-Mannanase activity was estimated by measuring the amount of reducing sugars released by using the dinitrosalicylic acid (DNS) method (Miller, 1959). Briefly, the reaction mixture containing $0.125 \mathrm{ml}$ of the desired dilution of enzyme and $0.125 \mathrm{ml}$ of $0.5 \%$ (w/v) locust bean gum in $0.1 \mathrm{M}$ sodium phosphate buffer $(\mathrm{pH} 6.5)$ was incubated at $37^{\circ} \mathrm{C}$ for $10 \mathrm{~min}$. The reaction was stopped by addition of $0.25 \mathrm{ml}$ of DNS (Sigma-Aldrich, St. Louis, MO, United States), then boiled for $10 \mathrm{~min}$, and $2 \mathrm{ml}$ of distilled water was added. The absorbance was measured at $540 \mathrm{~nm}$. One unit of $\beta$-mannanase activity was defined as the amount of enzyme that liberated $1 \mu \mathrm{mol}$ of reducing sugar per minute under the assay conditions. Cellulase, xylanase, pectinase, and amylase activities were also determined by the DNS method as described above, but $0.5 \%$ (w/v) of carboxymethyl cellulose (CMC), oat spelt xylan, pectin, and soluble starch in $0.1 \mathrm{M}$ sodium phosphate buffer ( $\mathrm{pH}$ 6.5) were specifically used as substrates for each enzyme.

\section{Sample Extraction for Bioactive Compound Analysis}

Miang samples were dried at $50^{\circ} \mathrm{C}$ for $24 \mathrm{~h}$ in a vacuum drier (Binder VD 23, Germany) and the dried sample was powdered and sieved through 60 mesh $(250 \mu \mathrm{m})$. A weight of $5 \mathrm{~g}$ of dry powdered Miang was extracted in $100 \mathrm{ml}$ of $80 \%$ (v/v) acetone on an incubator shaker at $30^{\circ} \mathrm{C}$ with $250 \mathrm{rpm}$ for $1 \mathrm{~h}$. After extraction, the extract was filtered through Whatman filter paper (No. 1) to remove any suspended material. The solvent was completely removed from the filtrate at $40^{\circ} \mathrm{C}$ for $20 \mathrm{~min}$ by an EYELA N-1000 rotary evaporator (Tokyo Rika-kikai Co. Ltd., Japan). Dried Miang extract was dissolved with $20 \mathrm{ml}$ of $80 \%$ $(\mathrm{v} / \mathrm{v})$ acetone, and the supernatant was used for the determination of total polyphenol content, total tannin, total flavonoid, and antioxidant activity based on DPPH free radical scavenging activity.

\section{Determination of Total Polyphenol Content}

The total polyphenol content (TP) in Miang extract was determined spectrophotometrically according to a modified method of Eom et al. (2008), with Folin-Ciocalteu reagent. Briefly, $200 \mu \mathrm{l}$ of the Miang extract sample was added into a test tube containing $200 \mu \mathrm{l}$ of $2 \mathrm{M}$ Folin-Ciocalteu reagent and vortexed. After adding $1.8 \mathrm{ml}$ of deionized water, the reaction mixture was incubated at room temperature for $3 \mathrm{~min}$. Then, $400 \mu \mathrm{l}$ of $10 \%(\mathrm{w} / \mathrm{v})$ sodium carbonate was added and vortexed. The final volume was adjusted to $4 \mathrm{ml}$ by deionized water and incubated in the dark at room temperature for $1 \mathrm{~h}$. The absorbance of blue coloration was measured at $725 \mathrm{~nm}$ using a spectrophotometer (Metertech SP8001, Taiwan) against a blank sample. Gallic acid was used as the standard and the results are expressed as milligrams of gallic acid equivalents (GAE) per gram of sample. 


\section{Determination of Total Tannin Content}

The total tannin content (TT) was determined by a modification of the Folin-Ciocalteu reagent according to Makkar et al. (1993) and using polyvinylpolypyrrolidone (PVPP) to separate tannins from other phenols. Briefly, $1 \mathrm{ml}$ of the Miang extract sample was mixed with $1 \mathrm{ml}$ of $10 \%(\mathrm{w} / \mathrm{v}) \mathrm{PVPP}$, vortexed, and kept at $4^{\circ} \mathrm{C}$ for $15 \mathrm{~min}$. Then, the reaction mixture was centrifuged at 3,000 rpm for $10 \mathrm{~min}$ and the supernatant was collected. The remaining total phenol content of PVPP precipitated supernatant was measured with the Folin-Ciocalteu reagent and TT was estimated by using the following formula: TT $=$ TP - PVPP precipitation. The results were expressed as milligrams of tannic acid equivalents (TAE) per gram of sample.

\section{Determination of Total Flavonoid Content}

The content of total flavonoids (TF) in Miang extracts was determined spectrophotometrically according to the aluminum chloride colorimetric method (Eom et al., 2008). In brief, $100 \mu \mathrm{l}$ of $10 \%(\mathrm{w} / \mathrm{v}$ ) aluminum nitrate and $100 \mu \mathrm{l}$ of $1 \mathrm{M}$ potassium acetate were mixed with $500 \mu \mathrm{l}$ of sample. Then, $3.3 \mathrm{ml}$ of $80 \%(\mathrm{v} / \mathrm{v})$ methanol was added to the reaction mixture and incubated for $40 \mathrm{~min}$. The absorbance of the combination was read at $415 \mathrm{~nm}$. Then, the absorbance values were converted to total flavonoid content expressed as milligrams of quercetin equivalents $(\mathrm{QE})$ per gram of sample.

\section{Free Radical Scavenging Ability by DPPH Inhibition Assay}

The antioxidant activity of the Miang extracts was analyzed according to the method reported by Braca et al. (2003) with minor modifications. This method is based on the scavenging activity of a stable 1,1-diphenyl-2-picrylhydrazyl (DPPH) free radical. In brief, $4 \mathrm{ml}$ of $0.15 \mathrm{mM}$ DPPH in ethanol solution was added to $1 \mathrm{ml}$ of diluted extract sample $(5,2.5,1.0$, and $0.5 \mathrm{mg} / \mathrm{ml})$ in deionized water and mixed vigorously. After $30 \mathrm{~min}$ of incubation in dark at room temperature, the absorbance was measured at $517 \mathrm{~nm}$. The radical scavenging percentage was calculated against a blank using the following equation:

$$
\text { Inhibition }(\%)=(1-(B / A)) \times 100
$$

where $A$ is the absorbance of the mixture without extract and $B$ is the absorbance of the mixture containing the extract of the samples. The percentage of inhibition was calculated and a graphic of percentage of inhibition versus concentration was constructed. The DPPH scavenging activities are expressed as $\mathrm{IC}_{50}$ value (half maximal inhibitory concentration).

\section{RESULTS AND DISCUSSION}

\section{Microbial Changes During Miang Fermentation Process}

Viable cell counts associated with Miang fermentation process were periodically enumerated throughout the fermentation period (Figure 1). LAB were found as the major microbial population from initial stages to throughout the fermentation period following by yeast and Bacillus. At the beginning of fermentation, the initial LAB, yeast, and Bacillus were approximately $2.5,1.2$, and $0.6 \log \mathrm{CFU} / \mathrm{g}$ dry weight $(\mathrm{dw})$, respectively, and all microbial abundance rapidly increased to the highest levels of approximately $6.8,4.2$, and $3.1 \log \mathrm{CFU} / \mathrm{g} \mathrm{dw}$, respectively, in just 3 days. However, LAB substantially decreased to $2.5 \log \mathrm{CFU} / \mathrm{g} \mathrm{dw}$ at day 84 , after which, it became stable at approximately $2.5 \log \mathrm{CFU} / \mathrm{g} \mathrm{dw}$ until the end of fermentation. Meanwhile, yeast and Bacillus cell numbers stabilized during day 3 to day 12 around 4.1 and $3.0 \log \mathrm{CFU} / \mathrm{g}$ dw, respectively, and then, both yeast and Bacillus numbers continuously declined to around 1.5 and $0.7 \log \mathrm{CFU} / \mathrm{g} \mathrm{dw}$, respectively, by day 21. After which, yeast number gradually rose to around 2.5 $\log \mathrm{CFU} / \mathrm{g} d \mathrm{~d}$ by the end of fermentation, whereas Bacillus number remained steady approximately at $2.2 \log \mathrm{CFU} / \mathrm{g}$ dw until the end of fermentation.

The results of viable cell number of all microbes markedly surged in the initial 3 days of fermentation, which indicated the log phase of microbial growth and the biomass was also doubled with every unit of time and linearly increased with time (Akerlund et al., 1995). After that, viable cell number of LAB tended to continuously decrease, while yeast and Bacillus tended to be stable during the entire fermentation period. This phenomenon is similar to the result of corresponding antagonistic relationship of yeasts and $\mathrm{LAB}$ in watery Kimchi (Jeong et al., 2013). Furthermore, mixed culture of microorganisms could affect various nutritional and biochemical changes in the fermentation process. The dynamics of fermentation in food matrix occurs by complex microbial processes via multiple mechanisms, which may have either positive, neutral, or negative impact on the fermentation process (Olanbiwoninu and Odunfa, 2018).

\section{Investigation on Bacterial and Fungal Community by Next-Generation Sequencing}

A total of $1,428,919$ sequencing reads were obtained from a single run of 7 bacterial and 7 fungal PCR amplicons. After the removal of low-quality and chimera sequences, 350,050 bacterial and 633,740 fungal high-quality sequences with an average read length of approximately 428 bp (bacterial) and 290 bp (fungal) and an average of more than 87,074 reads (bacterial) and 90,534 reads (fungal) per sample were obtained, and their statistical diversities were calculated (Table 1). The values of OTUs and bacterial diversity indices clearly showed that the bacterial diversities in Miang increased during the early fermentation period and then decreased markedly after 3 days of fermentation. On the other hand, the fungal diversities also increased at the beginning of the fermentation period and were relatively constant during the entire fermentation period. The high quality of bacterial 16S rRNA gene and fungal ITS sequences was classified at the phylum, family, genus, and species level in order to investigate the microbial community changes during the Miang fermentation. The bacterial diversity was presented in Figure 2. A total of 8 bacterial phyla, 60 families, and 88 genera were identified. The main bacterial 


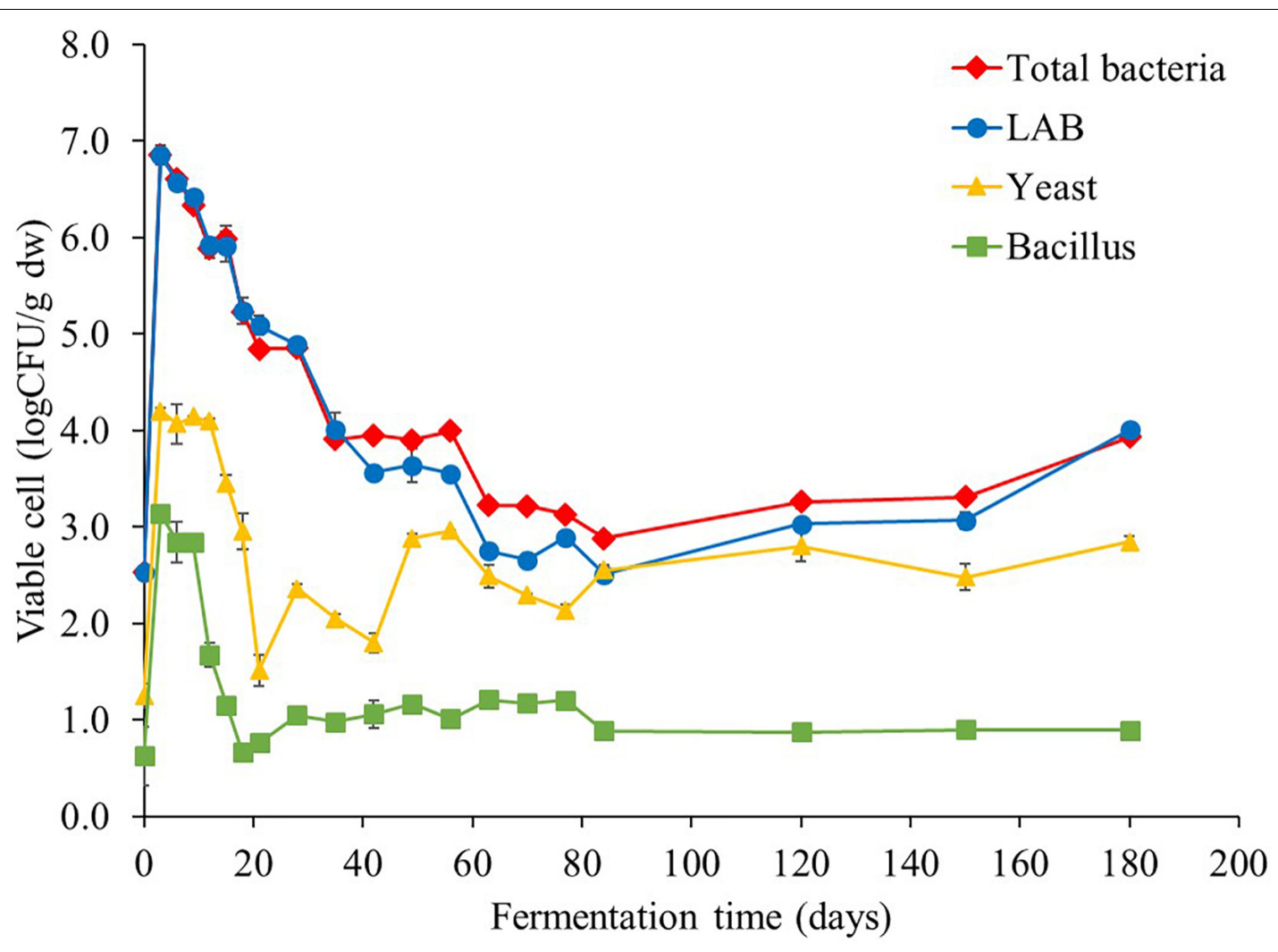

FIGURE 1 | Changes in microbial population during Miang fermentation process. The values were derived from triplicate Miang samples and error bars represent standard deviations.

phyla were assigned to the phylum Firmicutes (86.9-96.0\%) and Proteobacteria (4.0-12.4\%) (Figure 2A). The dominant bacterial families were Lactobacillaceae (39.7-79.5\%), Acetobacteraceae (5.2-21.4\%), Enterobacteriaceae (0.4-22.3\%), Bacillaceae (0.2-15.6\%), Aeromonadaceae (0.0-2.4\%), Staphylococcaceae (0.0-4.7\%), Moraxellaceae (0.0-1.5\%), Clostridiaceae (0.0-1.3\%), Exiguobacteraceae (0.0-1.2\%), Streptococcaceae (0.0-1.1\%), and Halomonadaceae (0.0-1.1\%) (Figure 2B). There were 18 dominant genera with an abundance over $1 \%$ including Lactobacillus (29.2-77.2\%), Acetobacter (3.8-22.8\%), Klebsiella (0.4-2.7\%), Plesiomonas (0.1-17.5\%), Bacillus (0.1-12.8\%), Exiguobacterium (0.0-6.6\%), Staphylococcus (0.0-4.1\%), Acinetobacter (0.0-4.1\%), Stenotrophomonas (0.0-2.6\%), Clostridium (0.0-2.5\%), Sphingomonas (0.0-2.5\%), Lactococcus (0.0-2.2\%), Halomonas (0.0-2.3\%), Pseudomonas (0.01.9\%), Agrobacterium (0.0-1.7\%), Streptococcus (0.0-1.6\%), Chitinibacter (0.0-1.2\%), and Cetobacterium (0.0-1.0\%) (Figure 2C). During the early fermentation period (day 3 and 6), the predominant bacteria were Lactobacillus followed by Acetobacter, Klebsiella, Plesiomonas, Bacillus, and Staphylococcus. However, the diverse bacterial community was replaced by Lactobacillus and Acetobacter as the fermentation progressed. The sequencing reads were further classified at the species level (Figure 2D). During early fermentation period (day 3), Lactobacillus plantarum (22.8\%), L. pentosus (20.2\%), Acetobacter aceti (4.1\%), Acetobacter pasteurianus (4.5\%), and
Bacillus cereus $(8.4 \%)$ were dominant. The observation was in agreement with results reported by Chaikaew et al. (2017), and the present study found that L. plantarum is the predominant species in Miang. It was also reported that Lactobacillus sp. occurred dominantly in various fermented tea products (Bo et al., 2020; Zhu et al., 2020).

In case of fungi, the fungal diversity was demonstrated in Figure 3. A total of 3 fungal phyla, 56 families, and 75 genera were found using amplicon sequencing. Ascomycota was the main fungal phylum with an abundance of over $99 \%$ in the community (Figure 3A). The dominant fungal family was incertae sedis Saccharomycetales (75.6-90.5\%) followed by Pichiaceae (8.1$14.9 \%)$, Pleosporaceae (0.0-2.2\%), Botryosphaeriaceae (0.0-1.9\%), Davidiellaceae (0.0-1.7\%), Mycosphaerellaceae (0.0-1.3\%), and Saccharomycodaceae (0.0-1.1\%) (Figure 3B). There were six dominant genera with an abundance over $1 \%$ including Candida (72.5-89.0\%), Pichia (8.1-14.9\%), Mycosphaerella (0.3$2.9 \%)$, Cyberlindnera (0.9-2.8\%), Debaryomyces (0.3-2.4\%), and Hanseniaspora (0.3-1.9\%) (Figure 3C). It was found that the genus level consisted of diverse groups during the initial fermentation period. After that, Candida and Pichia increased as the dominant genera with fermentation time. The sequencing reads were further classified at the species level (Figure 3D) and found that Candida boidinii (25.9-78.6\%), C. ethanolica (9.8-45.1\%), and Pichia manshurica (8.0-12.7\%) were dominant species and their communities were relatively stable. The result 
TABLE 1 | Summary of the sequencing data sets and statistical analysis of Miang fermentation samples.

\begin{tabular}{|c|c|c|c|c|c|c|c|c|}
\hline \multicolumn{2}{|c|}{ Fermentation time (day) } & \multirow{2}{*}{$\begin{array}{c}\begin{array}{c}\text { Total } \\
\text { reads }\end{array} \\
114,475\end{array}$} & \multirow{2}{*}{$\begin{array}{c}\text { High-quality } \\
\text { reads }\end{array}$} & \multirow{2}{*}{$\begin{array}{c}\text { Average read } \\
\text { length (bp) }\end{array}$} & \multirow{2}{*}{$\begin{array}{c}\text { OTUs } \\
98\end{array}$} & \multirow{2}{*}{$\begin{array}{c}\begin{array}{c}\text { Shannon-Weaver } \\
\text { index }\end{array} \\
2.07\end{array}$} & \multirow{2}{*}{$\begin{array}{c}\begin{array}{c}\text { Choat } \\
\text { index }\end{array} \\
132.42\end{array}$} & \multirow{2}{*}{$\begin{array}{c}\text { Good's } \\
\text { coverage }\end{array}$} \\
\hline Bacteria & 0 & & & & & & & \\
\hline & 3 & 107,486 & 61,330 & 428 & 170 & 2.24 & 145.67 & 99.8 \\
\hline & 6 & 105,370 & 49,144 & 429 & 120 & 1.82 & 117.33 & 99.5 \\
\hline & 14 & 110,773 & 40,244 & 429 & 112 & 1.84 & 125.00 & 99.8 \\
\hline & 28 & 111,566 & 61,195 & 429 & 83 & 1.54 & 118.30 & 99.6 \\
\hline & 56 & 103,882 & 55,029 & 427 & 71 & 1.26 & 106.13 & 99.9 \\
\hline & 120 & 86,185 & 29,676 & 428 & 54 & 1.04 & 30.87 & 99.7 \\
\hline & 180 & 107,874 & 53,432 & 429 & 31 & 1.08 & 47.75 & 99.5 \\
\hline \multirow[t]{8}{*}{ Fungi } & 0 & 102,342 & 94,754 & 291 & 124 & 2.23 & 157.61 & 99.7 \\
\hline & 3 & 92,703 & 84,214 & 291 & 166 & 2.52 & 165.00 & 99.5 \\
\hline & 6 & 99,702 & 91,718 & 290 & 172 & 2.56 & 175.12 & 99.6 \\
\hline & 14 & 101,280 & 92,170 & 293 & 191 & 2.62 & 188.51 & 99.4 \\
\hline & 28 & 104,960 & 95,308 & 291 & 183 & 2.30 & 186.03 & 99.8 \\
\hline & 56 & 90,014 & 81,808 & 291 & 149 & 2.37 & 219.00 & 99.7 \\
\hline & 120 & 108,354 & 98,302 & 289 & 145 & 2.18 & 154.37 & 99.8 \\
\hline & 180 & 98,770 & 90,220 & 288 & 97 & 1.26 & 104.23 & 99.5 \\
\hline
\end{tabular}

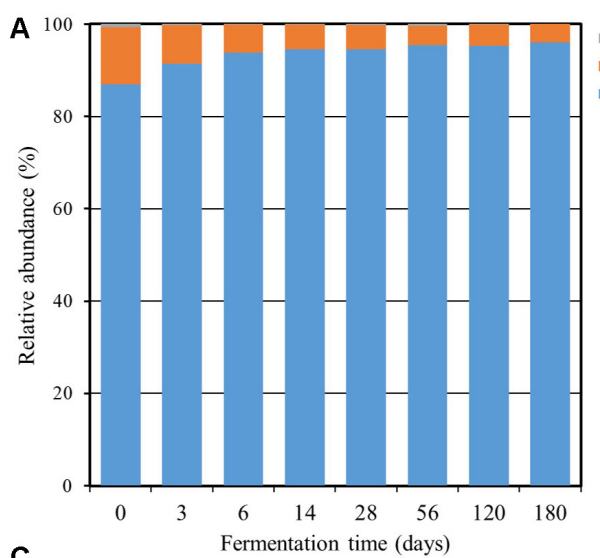

C

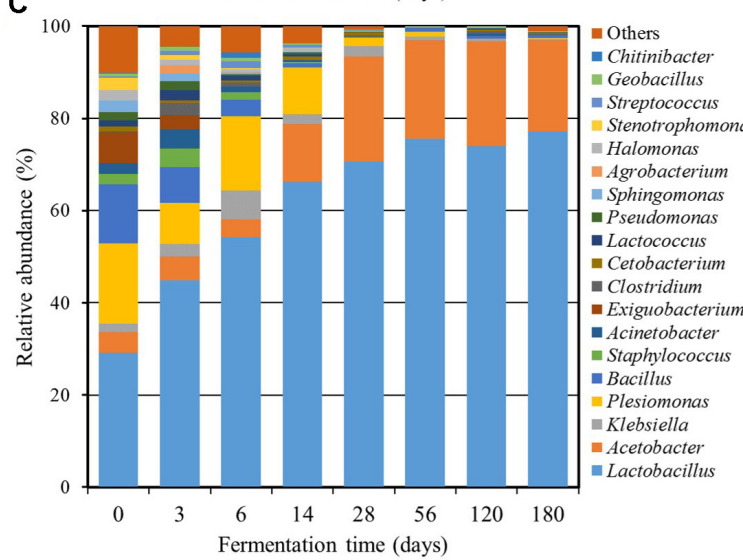

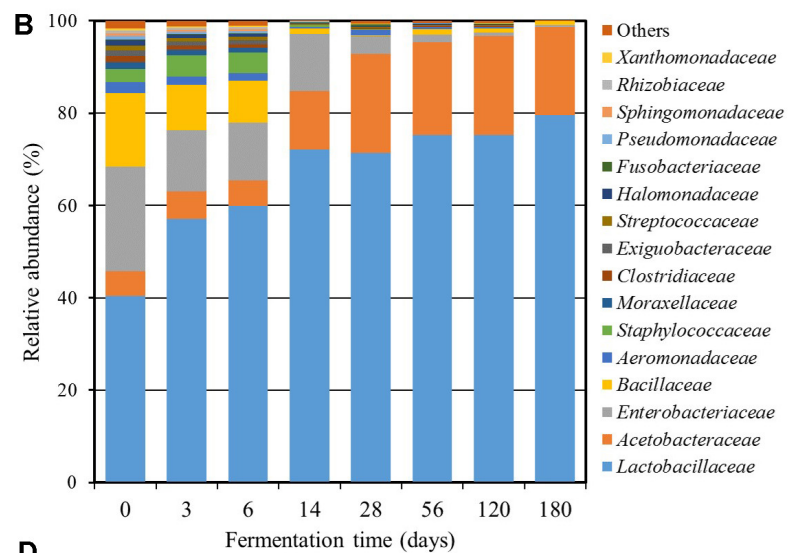

D

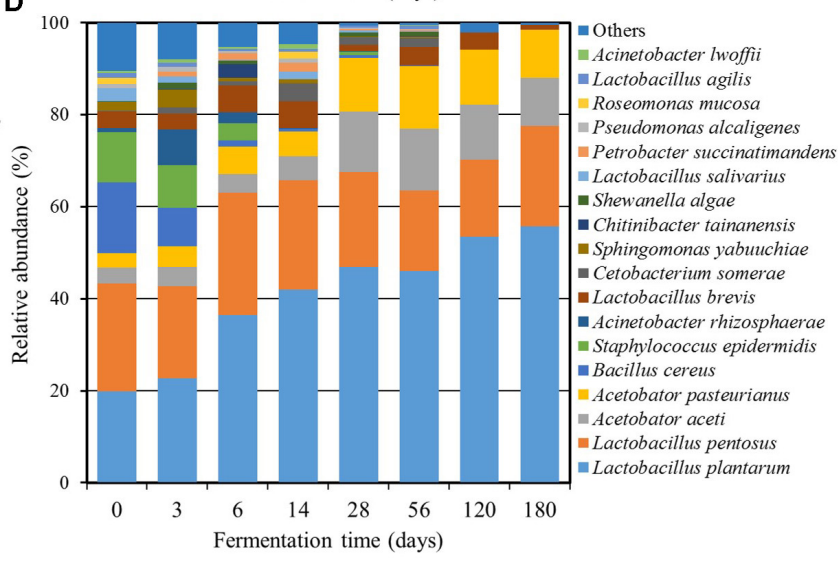

FIGURE 2 | Relative abundance of the bacterial community at the phylum (A), family (B), genus (C), and species (D) levels throughout the Miang fermentation period. The taxonomic abundance $<0.1 \%$ was classified into "others."

was in agreement with a previous report (Kanpiengjai et al., 2016), which found that C. ethanolica was the dominant species in the Miang sample collected from 28 sampling sites in upper northern Thailand. The genera Candida and Aspergillus were also found in some other types of fermented tea product, such as Fu brick tea and La phet (Li et al., 2017; Bo et al., 2020). 


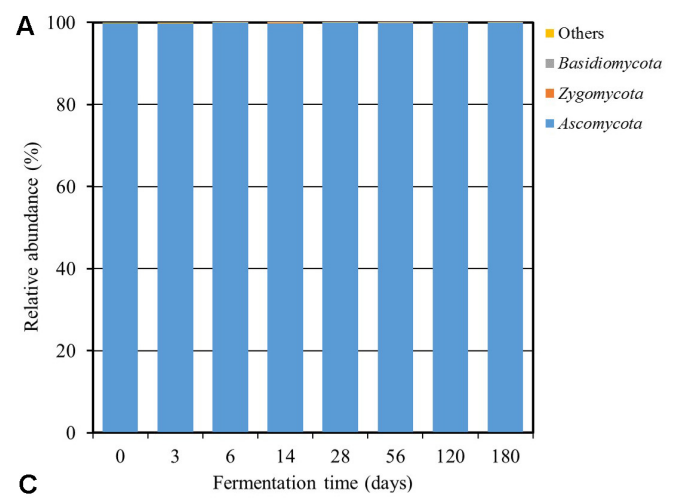

c

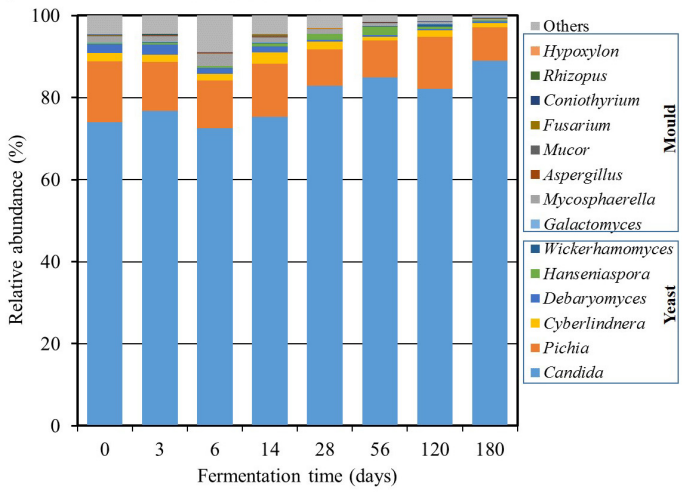

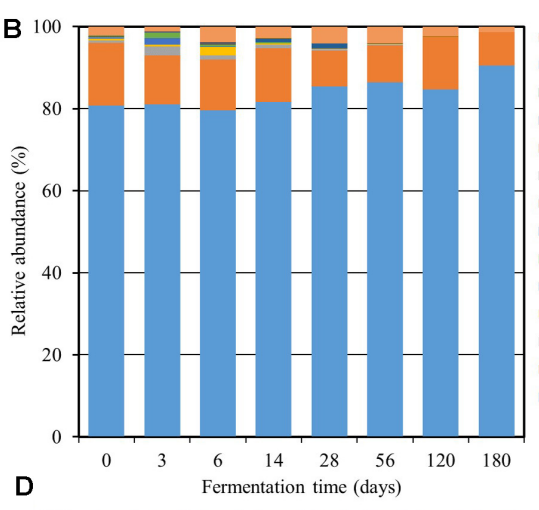

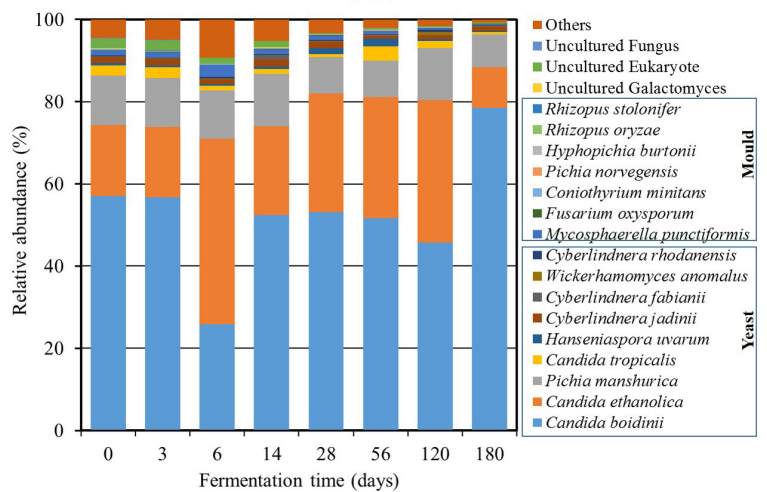

FIGURE 3 | Relative abundance of the fungal community at the phylum (A), family (B), genus (C), and species (D) levels throughout the Miang fermentation period. The taxonomic abundance $<0.1 \%$ was classified into "others."

Kanpiengjai et al. (2016) also suggested that yeast was involved in different profiles of chemical composition, flavors, qualities, and other unique characteristics of Miang. This included unique aroma constituents such as acetic acid and 4-ethylphenol. The secondary alcohols such as 2-butanol, 2-heptanol, (E)-4-hepten2-ol, and 1-octen-3-ol, as well as aromatic alcohols such as benzyl alcohol and 2-phenylethanol were also found.

In addition, to understand the variability among bacterial and fungal community structure during the fermentation process, PCA was performed (Figure 4). PCA based on bacterial 16S rRNA sequence data with PC1 and PC2 axes explained 36.46 and $18.10 \%$ of the variation in bacterial community differentiation, respectively. Meanwhile, PCA based on fungal ITS sequence data with PC1 and PC2 axes explained 33.31 and $23.21 \%$ of the variation in fungal community differentiation, respectively. The results suggest that the bacterial and fungal community structure during the Miang fermentation were changed significantly $(p<0.05)$ at the early stage of fermentation. Then, bacterial and fungal communities were clustered after 14 and 28 days of fermentation, respectively, indicating that microbial diversity changed slowly after these periods.

\section{Physico-Chemical Changes During Fermentation}

According to Figure $\mathbf{5 A}$, the initial $\mathrm{pH}$ value of Miang was approximately 5.0 and decreased rapidly to around 4.7 at day 3. Then, the $\mathrm{pH}$ values became stable in the range of 4.5 to 4.7 until the end of fermentation. The organic acids from NFP Miang samples were extracted and analyzed by HPLC and various organic acids such as glucuronic acid, tartaric acid, lactic acid, acetic acid, citric acid, succinic acid, gallic acid, and butyric acid were detected as presented in Figure 5B. Inconsistent with the $\mathrm{pH}$ values, the total acid content of the Miang sample rapidly increased to the maximum approximately $0.17 \mathrm{~g} / \mathrm{g} \mathrm{dw}$ after 12 days of fermentation and remained steady with slightly fluctuation until 40 days and then slowly decreased to approximately $0.08 \mathrm{~g} / \mathrm{g} \mathrm{dw}$ at the end of fermentation. Decrease of $\mathrm{pH}$ values and increase of total acid content in the beginning stage should be the result of acid producing by microorganisms such as LAB (Xiao et al., 2015) and yeast (Mugula et al., 2003; Narvhus and Gadaga, 2003; Arroyo-López et al., 2008). However, inconsistency between the $\mathrm{pH}$ and total acid content detected might be attributed to some buffering effects of the fermentation broth (Neffe-Skocińska et al., 2017). Furthermore, based on details of organic acid species presented in Figure 5B, at the beginning of fermentation, lactic and glucuronic acids were initially present in the sample and lactic acid was found as the main organic acid in the first 4 weeks. Acetic acid and succinic acid were later detected at 7 and 14 days, respectively. Regarding the $\mathrm{pH}$ changes described previously, the prompt increase of lactic acid and glucuronic acid during the early fermentation period may correlate well with the decrease in $\mathrm{pH}$ (Figure 5B). The amount of lactic acid observed was nearly two times higher than other acids in the early stage and 

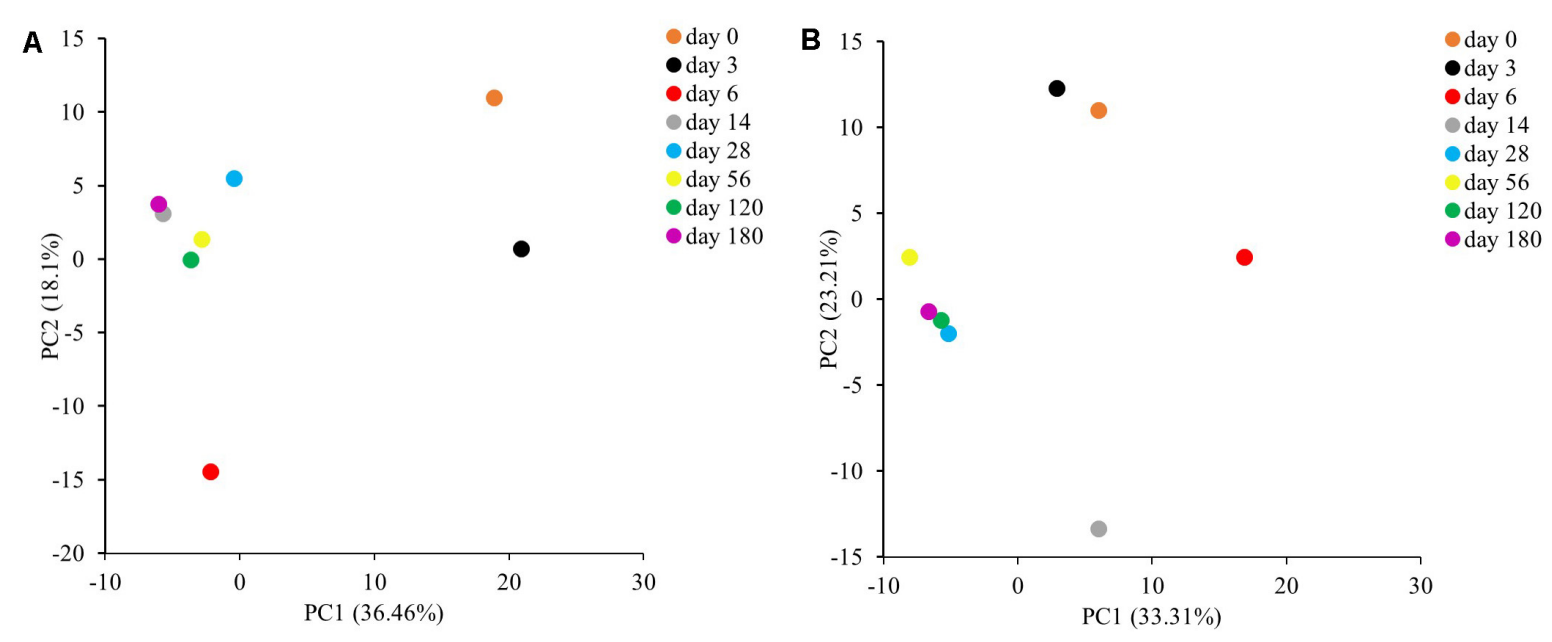

FIGURE 4 | Principal component analysis of bacterial (A) and fungal (B) communities in sample during the Miang fermentation process.

reached a maximum concentration of around $50.9 \mathrm{mg} / \mathrm{g} \mathrm{dw}$ at day 9 of fermentation, which was also correlated with the maximum growth of LAB population presented in NFP Miang samples described previously (Figure 1). Regarding the increase of glucuronic acid to a maximum of about $20 \mathrm{mg} / \mathrm{g} \mathrm{dw}$ at day 9, it has remained mostly stable until the end of fermentation. The well-known benefit of glucuronic acid is its detoxifying action through conjugation, which is also considered to be the important key component found in Kombucha tea (Jayabalan et al., 2007; Vina et al., 2013). Succinic acid is a by-product of yeast metabolism during fermentation (Tasev et al., 2016), increased maximum at 42-day and then tended to be stable to the end of fermentation. Interestingly, butyric acid was found at day 28 and increased rapidly to maximum concentration of 48.9 $\mathrm{mg} / \mathrm{g} \mathrm{dw}$ at 63 days of fermentation. Butyric acid is normally produced via glycolysis pathway by obligatory anaerobic sporeforming bacteria mainly and belong to the genus Clostridium (Jha et al., 2014). These bacterial group are able to oxidize sugar, and occasionally amylose and pectin to pyruvate and then to butyric acid (Ciani et al., 2008). The possible way of the Clostridium sp. growth is due to the likely decrease of oxygen concentration in the middle stage of Miang fermentation, which possibly occurred by oxygen consumption by aerobic bacteria at the early stage. Moreover, there is a growing number of reports describing the potential role of butyric acid related to treatment of hemoglobinopathies, cancer, and gastrointestinal diseases (Rephaeli et al., 2000; Encarnação et al., 2015). Further, in this study, gallic acid appeared throughout the fermentation period but a very low amount was detected.

Texture analysis was measured in terms of hardness (Figure 6A). At the beginning, the hardness of Miang was at $3.5 \times 10^{5} \mathrm{~N} / \mathrm{m}^{2}$ and then sharply declined to $1.5 \times 10^{5} \mathrm{~N} / \mathrm{m}^{2}$ after 12 days of fermentation. Subsequently, hardness of Miang remained constant at about $1.2 \times 10^{5} \mathrm{~N} / \mathrm{m}^{2}$ until the end of fermentation. Decreasing hardness in the early stage of fermentation was potentially due to $\beta$-mannanase activity (Chauhan et al., 2012). This could result in softness of steamed tea leaves due to breakdown of hemicellulose leading to softness (Mcdougall et al., 1993; Sharma et al., 1999). Beside the change of hardness, the color changes are also presented in Figure $\mathbf{6 A}$, where the $\mathrm{L}^{*}$ value represents the degree of lightness, and the higher it is, the lighter the color. The $\mathrm{a}^{*}$ value indicates redness when positive and greenness when negative, while the $b^{*}$ value reflects yellowness when positive and blueness when negative. For $L^{*}$ values, it significantly $(p<0.05)$ decreased from 44 at the beginning of fermentation to 38 at day 3 and then slowly decreased to 34 at the end of fermentation. For $a^{*}$ and $b^{*}$ values, the results indicated lack of significant change $(p<0.05)$ during the fermentation process. According to the result, it was found that only lightness had decreased. This might be caused by the oxidation of catechins to form larger molecules and non-volatile compounds such as theaflavins and thearubigins (Pou, 2016). Generally, the color of tea leaves is attributed to the phenolic compounds that they contain (Chaturvedula and Prakash, 2011) and to the oxidative enzymes (polyphenol oxidase), which could transform some phenolic compounds to phenolic pigments resulting in natural browning reaction (Kim et al., 2011).

\section{$\beta$-Mannanase and Pectinase Activity Profiles}

Various polysaccharide-degrading enzyme activities such as cellulases, $\beta$-mannanase, xylanase, amylase, and pectinase were investigated during the Miang fermentation process, but $\beta$-mannanase and pectinase were only two polysaccharidedegrading enzymes found in NFP Miang samples. At the early stage of fermentation, $19 \mathrm{U} / \mathrm{g} \mathrm{dw}$ of $\beta$-mannanase activity was detected and this increased to $43 \mathrm{U} / \mathrm{g} \mathrm{dw}$ at day 3 . Subsequently, the trend was rather stable until day 28 and reached up to $140 \mathrm{U} / \mathrm{g} \mathrm{dw}$ at the end of fermentation. However, very low amount of pectinase activity $(8.0 \mathrm{U} / \mathrm{g} \mathrm{dw})$ was detected in the early stage of fermentation and was continually stable until 180 days of fermentation. Changes in $\beta$-mannanase and pectinase activities corresponded to the decrease of hardness at the early 

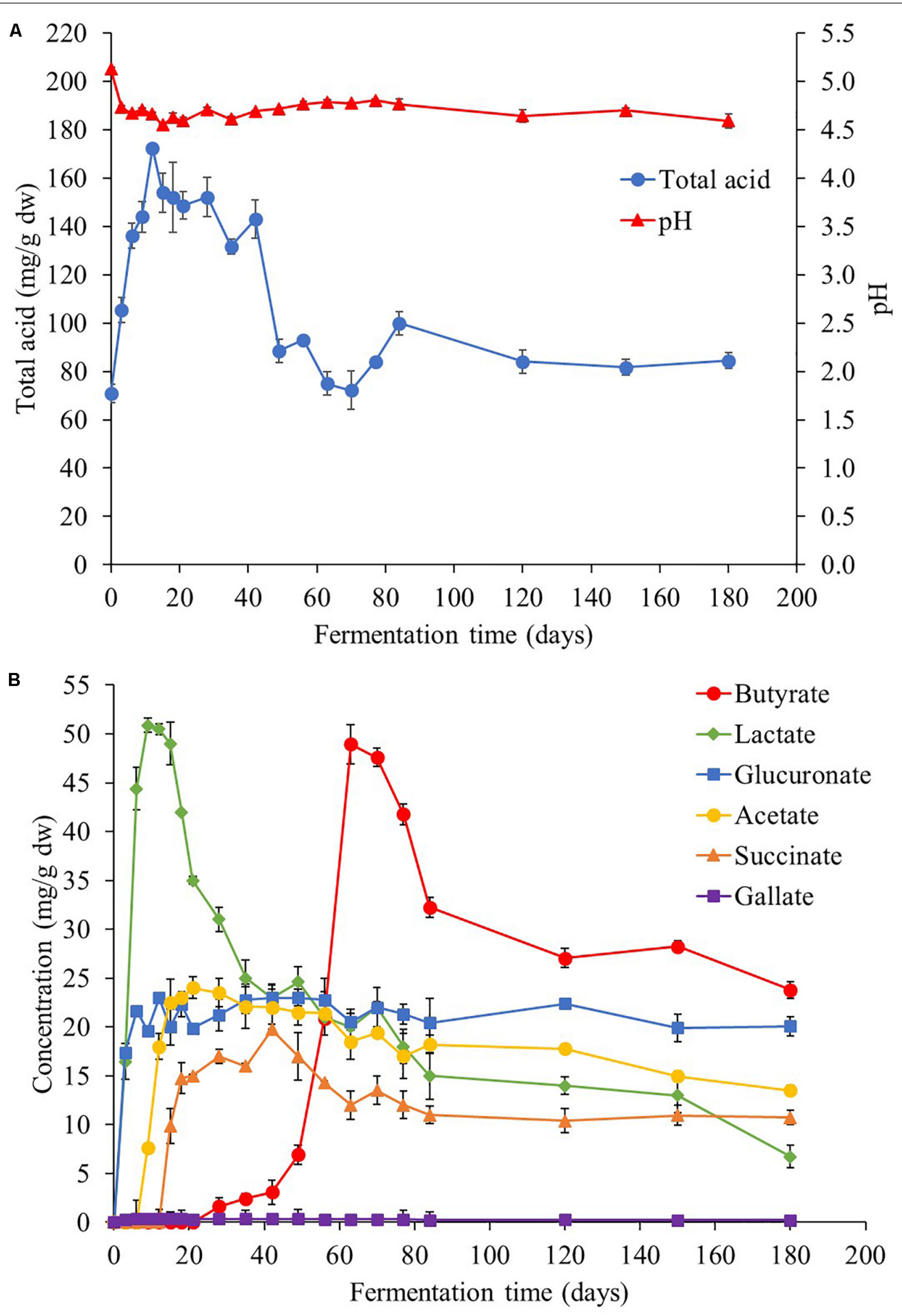

FIGURE 5 | Total acidity and pH (A) and organic acid profile (B) during the Miang fermentation process. The values were derived from triplicate Miang samples and error bars represent standard deviations.

stage of fermentation (Figure 6B). In correlation to the enzyme activity, the initial reducing sugar content was $0.09 \mathrm{~g} / \mathrm{g} \mathrm{dw}$ and then quickly increased to $0.15 \mathrm{~g} / \mathrm{g} \mathrm{dw}$ on day 6 . After that, it continuously increased to $0.25 \mathrm{~g} / \mathrm{g} \mathrm{dw}$ by the end of fermentation (Figure 6B). Tea leaves consist of 16.2\% cellulose, 68.2\% hemicellulose, and 18.8\% lignin (Rahman et al., 2017). These compositions could be degraded by enzymatic process of microorganisms, resulting in the released reducing sugar during 


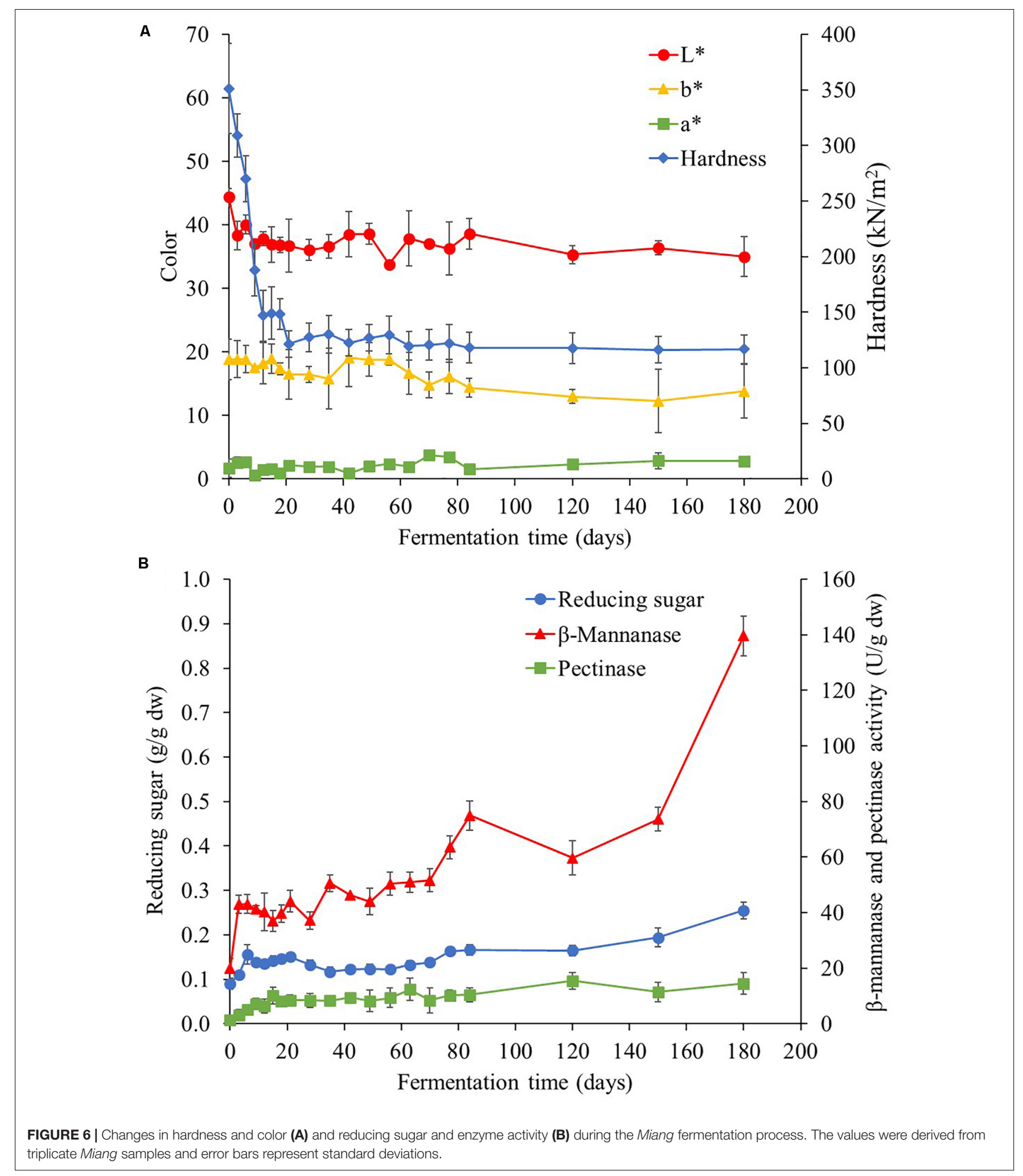

the fermentation process. This phenomenon might have been caused by high demand of nutrition for microbial growth and reproduction in the log phase (Akerlund et al., 1995). Moreover, the increase of reducing sugar in fermenting tea leaves might be the result of the hydrolysis of polysaccharides by $\beta$-mannanase, which was the main enzyme activity detected in the Miang sample. The detectable polysaccharide hydrolyzing enzymes such as $\beta$-mannanase and pectinase coincide with the rapid growth 
of the main microbial community such as LAB, which is normally unable to produce those two main enzymes, which therefore demonstrates the synergistic relationship with the other microbial communities during Miang fermentation. Potentially, $\beta$-mannanase activity is expected to be produced by the Bacillus spp. as these are found in high numbers and based on previous reports, suggesting the capability of $\beta$-mannanase production by various Bacilli (Khanongnuch et al., 1998; Zhang et al., 2000; Dhawan and Kaur, 2007; Chauhan et al., 2012). In a similar way, pectinase is possibly from either yeast or Bacillus spp., which was also found in high numbers during Miang fermentation. Therefore, the LAB utilize hydrolysis products from these two enzymes in the metabolic pathway through the succession process and finally produce lactic acid as the final product.

\section{Profiles of Bioactive Compounds and Antioxidant Activity}

This study found that TP contents were the major bioactive compounds in Miang during the fermentation period (Figure 7) followed by TT and the TF. At the initial fermentation period, TP and TT contents increased to 151 and $138 \mathrm{mg} / \mathrm{g} \mathrm{dw}$, respectively, by day 18 . After that, their trend was rather constant until 56 days of fermentation, following which contents decreased to 108 and $98 \mathrm{mg} / \mathrm{g} \mathrm{dw}$, respectively, on day 70 and then remained steady until the end of fermentation. For antioxidant activity, $\mathrm{IC}_{50}$ value tended to decrease from 34 to
$25 \mu \mathrm{g} / \mathrm{ml}$ from day 0 to day 6 and then remained steady until 56 days of fermentation and subsequently increased back to $34 \mu \mathrm{g} / \mathrm{ml}$ on day 70 . After this stage, it became stable until the end of fermentation. It was observed that after 70 days of fermentation, antioxidant activity decreased due to the decreasing of TP and TT. Change of bioactive compounds may be due to the ability of microorganisms to oxidize phenolic compounds of tea, leading to considerable loss of catechins and formation of theaflavins, thearubigins, theabrownins, and gallic acid (Kosińska and Andlauer, 2014). In addition, a previous report suggested that the yeast community mainly in the Candida sp. group was assumed to be associated with changes in the polyphenol and flavonoid contents in Kombucha (Chakravorty et al., 2016). Kanpiengjai et al. (2016) suggested that tannaseproducing yeasts may be involved in the formation of catechin and their derivatives in Miang production. From the results of this study, it could be suggested that the fermentation of Miang between 18 and 56 days of fermentation is the proper fermentation time for obtaining high antioxidant activity from the metabolic process. The major polyphenolic compounds of tea leaves are catechins (flavan-3-ols), which are efficient free radical scavengers due to their one-electron reduction potential. Along the Miang fermentation process, catechins were changed and the content of catechins during Miang fermentation is shown in Figure 8. Overall, total catechins slightly decreased from 37.8 to $31.5 \mathrm{mg} / \mathrm{g} \mathrm{dw}$ at the end of fermentation. GC was produced and increased from $3.6 \mathrm{mg} / \mathrm{g} \mathrm{dw}$ at day 3 to

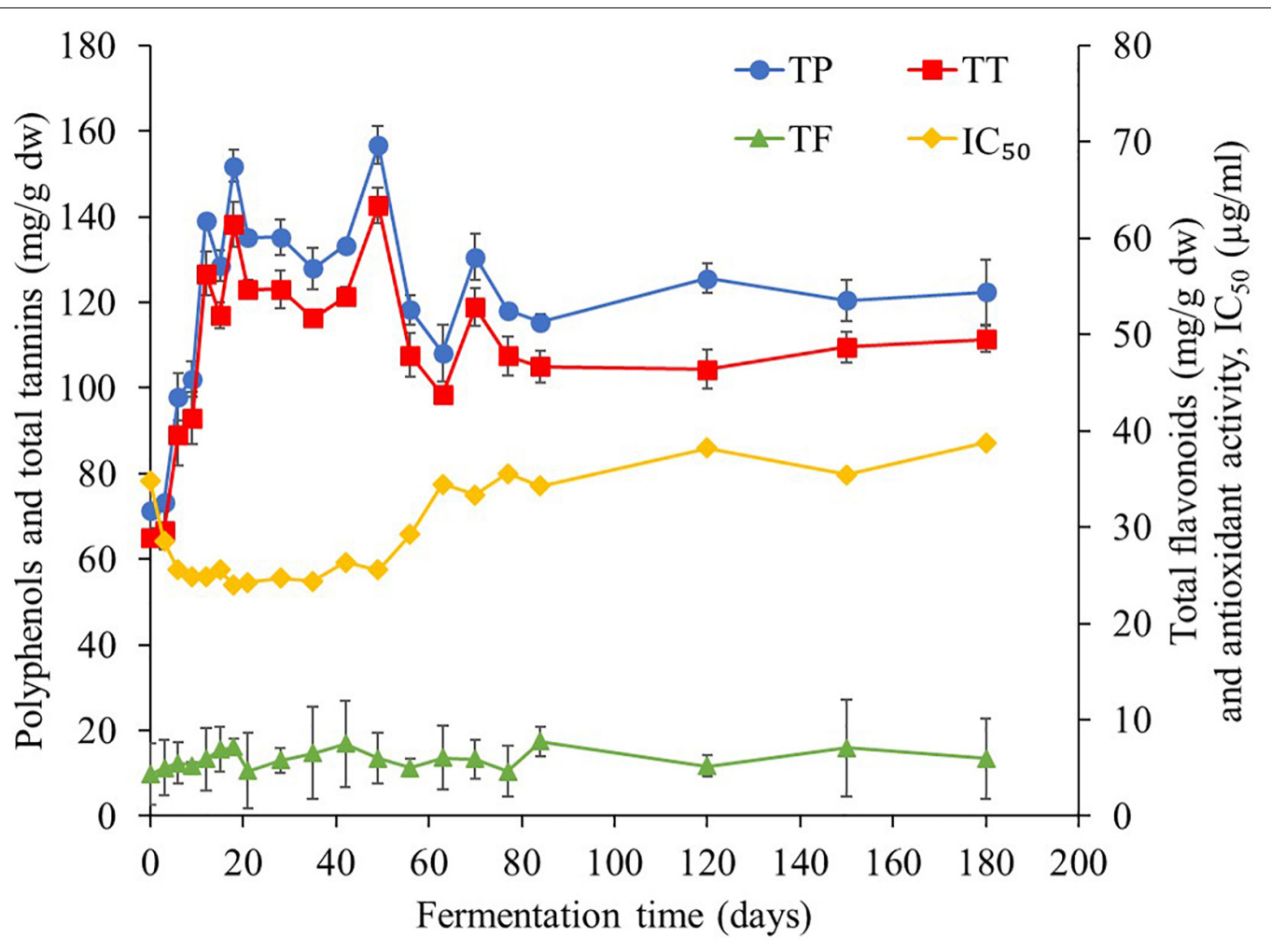

FIGURE 7 | Changes in total polyphenol, total tannin, total flavonoids, and antioxidant activity during the Miang fermentation process. The values were derived from triplicate Miang samples and error bars represent standard deviations. 


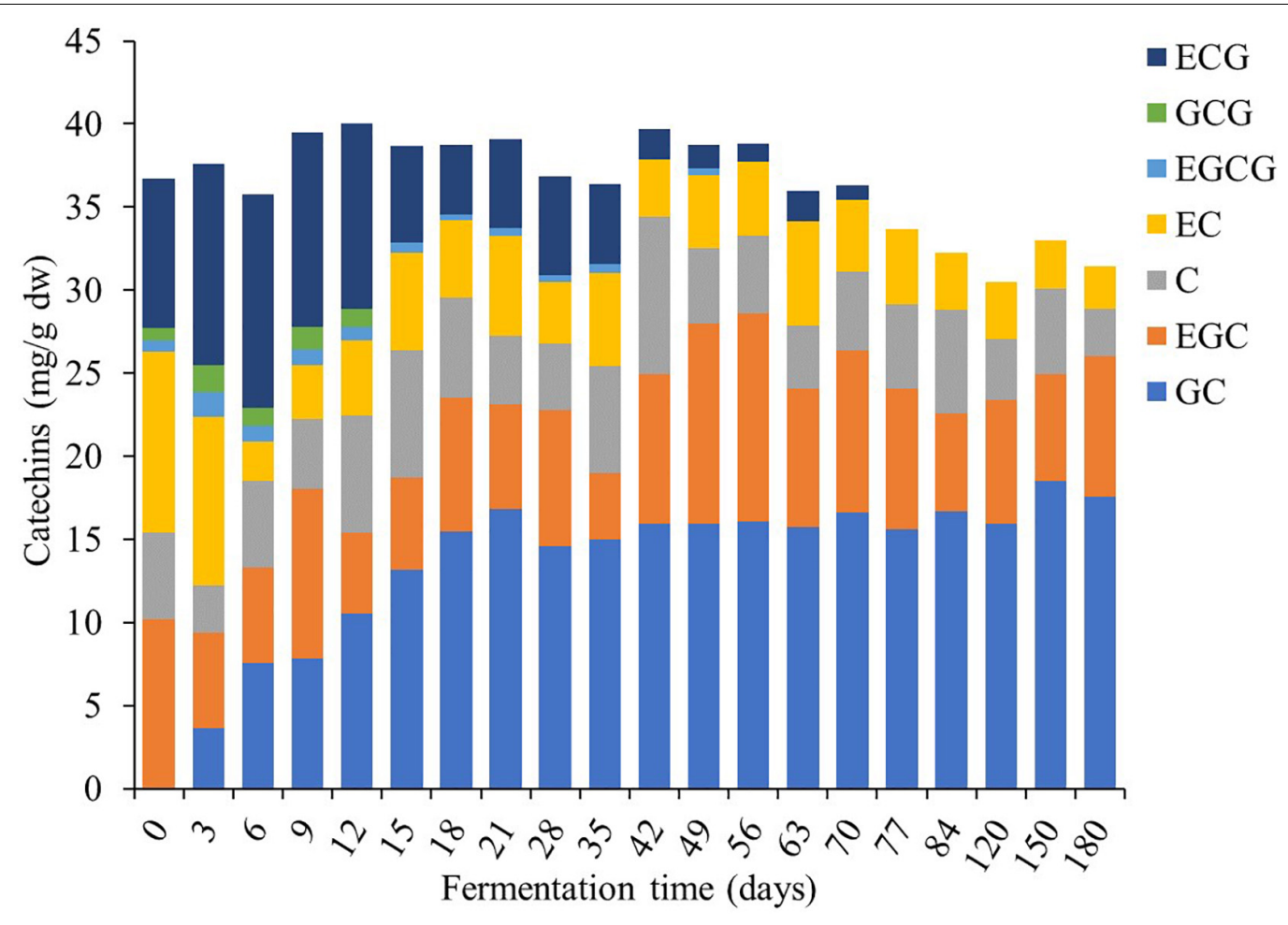

FIGURE 8 | Changes in catechins during the Miang fermentation process; (+)-gallocatechin (GC), (-)-epigallocatechin (EGC), (+)-catechin (C), (-)-epicatechin (EC), (-)-epigallocatechin gallate (EGCG), (+)-gallocatechin gallate (GCG), and (-)-epicatechin gallate (ECG).

$16.8 \mathrm{mg} / \mathrm{g} \mathrm{dw}$ at day 21 and then stable until the end of the fermentation process. After 12 days of fermentation, ECG, GCG, and EGCG began to decrease and were not detected at 77 days of fermentation, which is the end of process. It is assumed that ECG, GCG, and EGCG were converted to their corresponding catechin EC, GC, and EGC, respectively. Biotransformation of ECG, GCG, and EGCG to EC, GC, and EGC by microbial enzymes in Miang could be the main reason for the increased concentration of EC, GC, and EGC. These trends correspond to previous studies of tea catechin degradation during the microbial fermentation in fermented tea products (Noh et al., 2014; Li et al., 2018).

\section{CONCLUSION}

This study successfully evaluated the profiles of microbial communities during the fermentation of NFP Miang via culturedependent investigation and targeted culture-independent method using high-throughput sequencing. Lactobacillus was clearly found as the most dominant bacterial group followed by Acetobacter, while Candida and Pichia were found as the highest dominant population of fungi. Microbial changes also directly affect the physical and chemical properties of NFP Miang product, which were revealed by the $\mathrm{pH}$ values and organic acid profiles. The most interesting organic acid, butyric acid, was also detected in NFP Miang product. Moreover, the health-relevant bioactive compounds and antioxidant activity reached a maximum value by days $18-56$ of fermentation, which might be the most suitable stage to harvest and use Miang product for consumption. The results provide the basis to understand the mechanism of traditional fermented food, which is useful and essential for improving the industrial production of Miang. Further studies and future analyses of the association between the microorganisms and bioactive compounds that participate in Miang fermentation will help to advance knowledge for understanding the function of microorganisms in Miangbased traditional fermented foods, which can be targeted for applications and wider use.

\section{DATA AVAILABILITY STATEMENT}

The microbial metagenomic datasets generated for this study can be found in the Sequence Read Archive (SRA) at the NCBI under the BioProject under accession number PRJNA610188. The access link: http://www.ncbi.nlm.nih.gov/bioproject/610188.

\section{AUTHOR CONTRIBUTIONS}

KU, KS, and CK: conceptualization, writing — review and editing. $\mathrm{KU}$ and CK: methodology, writing-original draft preparation. $\mathrm{KU}$ and $\mathrm{NK}$ : formal analysis. KU, NK, TP, CS, and CK: investigation. KU: visualization. $\mathrm{CK}$ : supervision. All authors read and approved the final manuscript. 


\section{ACKNOWLEDGMENTS}

The authors are grateful to the Chiang Mai University for financial support via postdoctoral fellowship. This work was also partially supported by the National Research

\section{REFERENCES}

Akerlund, T., Nordström, K., and Bernander, R. (1995). Analysis of cell size and DNA content in exponentially growing and stationary-phase batch cultures of Escherichia coli. J. Bacteriol. 177, 6791-6797. doi: 10.1128/jb.177.23.6791-6797. 1995

AOAC (2012). Official Method of Analysis, 18th Edn. Washington DC: Association of official analytical chemists.

Arroyo-López, F., Querol, A., Bautista-Gallego, J., and Garrido-Fernández, A. (2008). Role of yeasts in table olive production. Int. J. Food Microbiol. 128, 189-196. doi: 10.1016/j.ijfoodmicro.2008.08.018

Bo, B., Kim, S. A., and Han, N. S. (2020). Bacterial and fungal diversity in Laphet, traditional fermented tea leaves in Myanmar, analyzed by culturing, DNA amplicon-based sequencing, and PCR-DGGE methods. Int. J. Food Microbiol. 320:108508. doi: 10.1016/j.ijfoodmicro.2020.108508

Braca, A., Fico, G., Morelli, I., De Simone, F., Tomè, F., and De Tommasi, N. (2003). Antioxidant and free radical scavenging activity of flavonol glycosides from different Aconitum species. J. Ethnopharmacol. 86, 63-67. doi: 10.1016/ S0378-8741(03)00043-6

Caporaso, J. G., Kuczynski, J., Stombaugh, J., Bittinger, K., Bushman, F. D., Costello, E. K., et al. (2010). QIIME allows analysis of high-throughput community sequencing data. Nat. Methods 7, 335-336. doi: 10.1038/nmeth. f.303

Chaikaew, S., Baipong, S., Sone, T., Kanpiengjai, A., Chui-Chai, N., Asano, K., et al. (2017). Diversity of lactic acid bacteria from Miang, a traditional fermented tea leaf in northern Thailand and their tannin-tolerant ability in tea extract. J. Microbiol. 55, 720-729. doi: 10.1007/s12275-017-7195-8

Chakravorty, S., Bhattacharya, S., Chatzinotas, A., Chakraborty, W., Bhattacharya, D., and Gachhui, R. (2016). Kombucha tea fermentation: microbial and biochemical dynamics. Int. J. Food Microbiol. 220, 63-72. doi: 10.1016/j. ijfoodmicro.2015.12.015

Chao, A. (1987). Estimating the population size for capture-recapture data with unequal catchability. Biometrics 43, 783-791. doi: 10.2307/2531532

Chaturvedula, V. S. P., and Prakash, I. (2011). The aroma, taste, color and bioactive constituents of tea. J. Med. Plants Res. 5, 2110-2124.

Chauhan, P. S., Puri, N., Sharma, P., and Gupta, N. (2012). Mannanases: microbial sources, production, properties and potential biotechnological applications. Appl. Microbiol. Biotechnol. 93, 1817-1830. doi: 10.1007/s00253-0123887-5

Ciani, M., Comitini, F., and Mannazzu, I. (2008). "Fermentation," in Encyclopedia of Ecology, eds S. E. Jørgensen and B. D. Fath (Oxford: Academic Press), 1548-1557.

Desantis, T. Z., Hugenholtz, P., Larsen, N., Rojas, M., Brodie, E. L., Keller, K., et al. (2006). Greengenes, a chimera-checked 16S rRNA gene database and workbench compatible with ARB. Appl. Environ. Microbiol. 72, 5069-5072. doi: 10.1128/AEM.03006-05

Dhawan, S., and Kaur, J. (2007). Microbial mannanases: an overview of production and applications. Crit. Rev. Biotechnol. 27, 197-216. doi: 10.1080/ 07388550701775919

Edgar, R. C. (2013). UPARSE: highly accurate OTU sequences from microbial amplicon reads. Nat. Methods 10, 996-998. doi: 10.1038/nmeth.2604

Encarnação, J., Abrantes, A., Pires, A., and Botelho, M. (2015). Revisit dietary fiber on colorectal cancer: butyrate and its role on prevention and treatment. Cancer Metastasis Rev. 34, 465-478. doi: 10.1007/s10555-015-9578-9

Eom, S. H., Park, H. J., Jin, C. W., Kim, D. O., Seo, D. W., Jeong, Y. H., et al. (2008). Changes in antioxidant activity with temperature and time in Chrysanthemum indicum L.(Gamguk) teas during elution processes in hot water. Food Sci. Biotechnol. 17, 408-412.

Han, Y., Du, J., Li, J., and Li, M. (2019). Quantification of the organic acids in hawthorn wine: a comparison of two HPLC methods. Molecules 24:2150. doi: $10.3390 /$ molecules 24112150
Council of Thailand (NRCT) and Agricultural Research Development Agency (ARDA). The authors would like to thank the Division of Biotechnology, School of AgroIndustry, Faculty of Agro-Industry, Chiang Mai University, for their facilities.

Huang, Y., Liu, C., and Xiao, X. (2016). Quality characteristics of a pickled tea processed by submerged fermentation. Int. J. Food Prop. 19, 1194-1206. doi: 10.1080/10942912.2015.1075217

Jayabalan, R., Marimuthu, S., and Swaminathan, K. (2007). Changes in content of organic acids and tea polyphenols during kombucha tea fermentation. Food Chem. 102, 392-398. doi: 10.1016/j.foodchem.2006.05.032

Jeong, S. H., Lee, S. H., Jung, J. Y., Choi, E. J., and Jeon, C. O. (2013). Microbial succession and metabolite changes during long-term storage of Kimchi. J. Food Sci. 78, M763-M769. doi: 10.1111/1750-3841.12095

Jha, A. K., Li, J., Yuan, Y., Baral, N., and Ai, B. (2014). A review on bio-butyric acid production and its optimization. Int. J. Agric. Biol. 16, 1019-1024.

Kanpiengjai, A., Chui-Chai, N., Chaikaew, S., and Khanongnuch, C. (2016). Distribution of tannin-tolerant yeasts isolated from Miang, a traditional fermented tea leaf (Camellia sinensis var. assamica) in northern Thailand. Int. J. Food Microbiol. 238, 121-131. doi: 10.1016/j.ijfoodmicro.2016.08.044

Kawakami, M., Chairote, G., and Kobayashi, A. (1987). Flavor constituents of pickled tea, miang, in thailand. Agric. Biol. Chem. 51, 1683-1687. doi: 10.1271/ bbb1961.51.1683

Khanongnuch, C., Asada, K., Tsuruga, H., Ooi, T., Kinoshita, S., and Lumyong, S. (1998). $\beta$-Mannanase and xylanase of Bacillus subtilis $5 \mathrm{H}$ active for bleaching of crude pulp. J. Ferment. Bioeng. 86, 461-466. doi: 10.1016/S0922-338X(98) 80152-9

Khanongnuch, C., Unban, K., Kanpiengjai, A., and Saenjum, C. (2017). Recent research advances and ethno-botanical history of miang, a traditional fermented tea (Camellia sinensis var. assamica) of Northern Thailand. J. Ethn. Foods 4, 135-144. doi: 10.1016/j.jef.2017.08.006

Kim, Y., Goodner, K. L., Park, J. D., Choi, J., and Talcott, S. T. (2011). Changes in antioxidant phytochemicals and volatile composition of Camellia sinensis by oxidation during tea fermentation. Food Chem. 129, 1331-1342. doi: 10.1016/j. foodchem.2011.05.012

Kõljalg, U., Nilsson, R. H., Abarenkov, K., Tedersoo, L., Taylor, A. F., Bahram, M., et al. (2013). Towards a unified paradigm for sequence-based identification of fungi. Mol. Ecol. 22, 5271-5277. doi: 10.1111/mec.12481

Kosińska, A., and Andlauer, W. (2014). "Antioxidant capacity of tea: effect of processing and storage," in Processing and Impact on Antioxidants in Beverages, Ed. V. Preedy (Amsterdam: Elsevier), 109-120. doi: 10.1016/b9780-12-404738-9.00012-x

Li, Q., Huang, J., Li, Y., Zhang, Y., Luo, Y., Chen, Y., et al. (2017). Fungal community succession and major components change during manufacturing process of Fu brick tea. Sci. Rep. 7, 1-9.

Li, Z., Feng, C., Luo, X., Yao, H., Zhang, D., and Zhang, T. (2018). Revealing the influence of microbiota on the quality of Pu-erh tea during fermentation process by shotgun metagenomic and metabolomic analysis. Food Microbiol. 76, 405-415. doi: 10.1016/j.fm.2018.07.001

Liang, H., Chen, H., Ji, C., Lin, X., Zhang, W., and Li, L. (2018). Dynamic and functional characteristics of predominant species in industrial paocai as revealed by combined DGGE and metagenomic sequencing. Front. Microbiol. 9:2416. doi: 10.3389/fmicb.2018.02416

Loman, N. J., Misra, R. V., Dallman, T. J., Constantinidou, C., Gharbia, S. E., Wain, J., et al. (2012). Performance comparison of benchtop high-throughput sequencing platforms. Nat. Biotechnol. 30, 434-349. doi: 10.1038/nbt.2198

Magoč, T., and Salzberg, S. L. (2011). FLASH: fast length adjustment of short reads to improve genome assemblies. Bioinformatics 27, 2957-2963. doi: 10.1093/ bioinformatics/btr507

Makkar, H. P., Blümmel, M., Borowy, N. K., and Becker, K. (1993). Gravimetric determination of tannins and their correlations with chemical and protein precipitation methods. J. Sci. Food Agric. 61, 161-165. doi: 10.1002/jsfa. 2740610205

Mcdougall, G. J., Morrison, I. M., Stewart, D., Weyers, J. D. B., and Hillman, J. R. (1993). Plant fibres: botany, chemistry and processing for industrial use. J. Sci. Food Agric. 62, 1-20. doi: 10.1002/jsfa.2740620102 
Miller, G. L. (1959). Use of dinitrosalicylic acid reagent for determination of reducing sugar. Anal. Chem. 31, 426-428. doi: 10.1021/ac60147a030

Mugula, J. K., Narvhus, J. A., and Sørhaug, T. (2003). Use of starter cultures of lactic acid bacteria and yeasts in the preparation of togwa, a Tanzanian fermented food. Int. J. Food Microbiol. 83, 307-318. doi: 10.1016/S0168-1605(02)00386-0

Narvhus, J. A., and Gadaga, T. H. (2003). The role of interaction between yeasts and lactic acid bacteria in African fermented milks: a review. Int. J. Food Microbiol. 86, 51-60. doi: 10.1016/S0168-1605(03)00247-2

Neffe-Skocińska, K., Sionek, B., Ścibisz, I., and Kołożyn-Krajewska, D. (2017). Acid contents and the effect of fermentation condition of Kombucha tea beverages on physicochemical, microbiological and sensory properties. CyTA J. Food 15, 601-607. doi: 10.1080/19476337.2017.1321588

Noh, D. O., Choi, H. S., and Suh, H. J. (2014). Catechine biotransformation by tannase with sequential addition of substrate. Process Biochem. 49, 271-276. doi: 10.1016/j.procbio.2013.11.001

Okada, S., Daengsubha, W., Uchimura, T., Ohara, N., and Kozaki, M. (1986). Flora of lactic acid bacteria in miang produced in northern Thailand. J. Gen. Appl. Microbiol. 32, 57-65. doi: 10.2323/jgam.32.57

Olanbiwoninu, A. A., and Odunfa, S. A. (2018). Microbial interaction in selected fermented vegetable condiments in Nigeria. Int. Food Res. J. 25, 439-455.

Pou, K. R. J. (2016). Fermentation: the key step in the processing of black tea. J. Biosyst. Eng. 41, 85-92. doi: 10.5307/JBE.2016.41.2.085

Rahman, A., Hayati, N., Chieng, B. W., Lbrahim, N. A., and Abdul Rahman, N. (2017). Extraction and characterization of cellulose nanocrystals from tea leaf waste fibers. Polymers 9:588. doi: 10.3390/polym9110588

Rephaeli, A., Zhuk, R., and Nudelman, A. (2000). Prodrugs of butyric acid from bench to bedside: synthetic design, mechanisms of action, and clinical applications. Drug Dev. Res. 50, 379-391. doi: 10.1002/1098-2299(200007/08) 50:3/4<379:AID-DDR20<3.0.CO;2-8

Santana, M. A., Moccia-V, C. C., and Gillis, A. (2008). Bacillus thuringiensis improved isolation methodology from soil samples. J. Microbiol. Methods 75, 357-358. doi: 10.1016/j.mimet.2008.06.008

Shannon, C. E., and Weaver, W. (1963). A Mathematical Theory of Communication. Illinois: University of Illinois Press.

Sharma, H. S. S., Faughey, G., and Lyons, G. (1999). Comparison of physical, chemical, and thermal characteristics of water-, dew-, and enzyme-retted flax fibers. J. Appl. Polym. Sci. 74, 139-143. doi: 10.1002/(SICI)10974628(19991003)74:1<139:AID-APP17<3.0.CO;2-E

Sukontasing, S., Tanasupawat, S., Moonmangmee, S., Lee, J. S., and Suzuki, K. I. (2007). Enterococcus camelliae sp. nov., isolated from fermented tea leaves in Thailand. Int. J. Syst. Evol. Microbiol. 57, 2151-2154. doi: 10.1099/ijs.0.65109-0
Tan, G., Hu, M., Li, X., Pan, Z., Li, M., Li, L., et al. (2020). High-throughput sequencing and metabolomics reveal differences in bacterial diversity and metabolites between red and white Sufu. Front. Microbiol. 11:758. doi: 10.3389/ fmicb.2020.00758

Tanasupawat, S., Pakdeeto, A., Thawai, C., Yukphan, P., and Okada, S. (2007). Identification of lactic acid bacteria from fermented tea leaves (miang) in Thailand and proposals of Lactobacillus thailandensis sp. nov. Lactobacillus camelliae sp. nov., and Pediococcus siamensis sp. nov. J. Gen. Appl. Microbiol. 53, 7-15. doi: 10.2323/jgam.53.7

Tasev, K., Stefova, M., and Ivanova, V. (2016). HPLC method validation and application for organic acid analysis in wine after solid-phase extraction. Maced. J. Chem. Chem. Eng. 35, 225-233.

Unban, K., Khatthongngam, N., Shetty, K., and Khanongnuch, C. (2019). Nutritional biotransformation in traditional fermented tea (Miang) from north Thailand and its impact on antioxidant and antimicrobial activities. J. Food Sci. Technol. 56, 2687-2699. doi: 10.1007/s13197-019-03758-x

Vina, I., Semjonovs, P., Linde, R., and Patetko, A. (2013). Glucuronic acid containing fermented functional beverages produced by natural yeasts and bacteria associations. Int. J. Res. Rev. Appl. Sci. 14, 17-25.

Xiao, P., Huang, Y., Yang, W., Zhang, B., and Quan, X. (2015). Screening lactic acid bacteria with high yielding-acid capacity from pickled tea for their potential uses of inoculating to ferment tea products. J. Food Sci. Technol. 52, 6727-6734. doi: 10.1007/s13197-015-1803-6

Zhang, J., He, Z., and Hu, K. (2000). Purification and characterization of $\beta$ mannanase from Bacillus licheniformis for industrial use. Biotechnol. Lett. 22, 1375-1378. doi: 10.1023/A:1005644414762

Zhu, M. Z., Li, N., Zhou, F., Ouyang, J., Lu, D. M., Xu, W., et al. (2020). Microbial bioconversion of the chemical components in dark tea. Food Chem. 312:126043. doi: 10.1016/j.foodchem.2019.126043

Conflict of Interest: The authors declare that the research was conducted in the absence of any commercial or financial relationships that could be construed as a potential conflict of interest.

Copyright (c) 2020 Unban, Khatthongngam, Pattananandecha, Saenjum, Shetty and Khanongnuch. This is an open-access article distributed under the terms of the Creative Commons Attribution License (CC BY). The use, distribution or reproduction in other forums is permitted, provided the original author(s) and the copyright owner(s) are credited and that the original publication in this journal is cited, in accordance with accepted academic practice. No use, distribution or reproduction is permitted which does not comply with these terms. 